\title{
Gendered Perspectives on Climate Change Adaptation: A Quest for Social Sustainability in Badlagaree Village, Bangladesh
}

\author{
M. Anwar Hossen ${ }^{1, *}$ D, David Benson ${ }^{2}$, Syeda Zakia Hossain ${ }^{3}$, Zakia Sultana ${ }^{1}$ and Md. Mizanur Rahman ${ }^{4}$ \\ 1 Department of Sociology, University of Dhaka, Dhaka 1000, Bangladesh; szakia60@gmail.com \\ 2 College of Social Sciences and International Studies, University of Exeter, Exeter EX4 4PY, UK; \\ d.i.benson@exeter.ac.uk \\ 3 Faculty of Medicine and Health, The University of Sydney, Sydney, NSW 2006, Australia \\ zakia.hossain@sydney.edu.au \\ 4 Department of Environment and Development Studies, United International University, \\ Dhaka 1212, Bangladesh; mizanur@idss.uiu.ac.bd \\ * Correspondence: anwar_sociology@du.ac.bd
}

check for updates

Citation: Hossen, M.A.; Benson, D.; Hossain, S.Z.; Sultana, Z.; Rahman, M.M. Gendered Perspectives on Climate Change Adaptation: A Quest for Social Sustainability in Badlagaree Village, Bangladesh. Water 2021, 13, 1922. https://doi.org/10.3390/ w13141922

Academic Editors: Ming Hsu Li, Ian Holman and Ching-pin Tung

Received: 9 June 2021

Accepted: 8 July 2021

Published: 12 July 2021

Publisher's Note: MDPI stays neutral with regard to jurisdictional claims in published maps and institutional affiliations.

Copyright: (c) 2021 by the authors. Licensee MDPI, Basel, Switzerland. This article is an open access article distributed under the terms and conditions of the Creative Commons Attribution (CC BY) license (https:/ / creativecommons.org/licenses/by/ $4.0 /)$.

\begin{abstract}
Climate change effects cause major socioeconomic challenges for marginalized groups, particularly women, in Bangladesh. Specifically, drought increases resource scarcity, causing social problems that impact women, which can be described as the gendered sociocultural construction of vulnerabilities. Given this constructed dimension of gender-based vulnerability, this paper explores the effects of drought on marginalized women in one local case study, namely Badlagaree village in Gaibandha district, Bangladesh. To examine this linkage, we collected qualitative primary data using ethnographic research methods, primarily focus group discussions. Findings show that gender-based vulnerability is increasing due to growing drought effects, including agricultural production loss. Marginalized women, because of their gender identity, encounter these drought effects through unemployment, food insecurity, illiteracy, early marriage, dowry costs and violence. While further national-scale research is required, this paper argues that in order to overcome such gender-based vulnerability, current development policies, social programs, and adaptation strategies should better recognize such social dynamics. Further, a gender-specific understanding requires incorporation into adaptation policies through greater collaborative governance as an important prerequisite for sustainability.
\end{abstract}

Keywords: climate change; drought; gender; social vulnerability; violence against women; social development; adaptation; sustainability

\section{Introduction}

Climate change is the most challenging threat the world faces today. It is characterized by weather irregularity and rising sea levels, causing widespread vulnerabilities. The Intergovernmental Panel on Climate Change [1] defines the concept of vulnerability, as 'the degree to which a system is susceptible to, or unable to cope with, adverse effects of climate change, including climate variability and extremes'. In relation to climate change, 'vulnerability research has sought to identify where, how, and why human systems are affected by changes in the climate', with a growing body of academic studies published on this subject [2]. Such studies predict that climate change will increase the vulnerabilities of different human populations, particularly through impacting the resilience of water resources [3]. Here, Bangladesh is recognized globally as one of the countries most vulnerable to climate change due to its geographical position, low-lying situation and high population densities [4]. Vulnerabilities in this context are related to multiple climate change effects, including flooding, cyclones, sea-level rise and drought $[5,6]$.

Drought is already a recurrent problem in Bangladesh, mainly in vulnerable northern regions [6,7]. Over the past 50 years, the country has endured over 20 major droughts [8]. 
Although droughts historically occur during the dry winter season, under climate change, these events are predicted to increase in both severity and frequency [9]; see also [6,8]. There is also significant regional variation in drought events [9]. For example, $77 \%$ of the northwestern part of Bangladesh is considered moderately to extremely vulnerable to these events [10]. Rainfall is relatively insignificant and drought is a frequent natural event, with the region considered semi-arid [6]. As rainfall is the primary source of groundwater recharge, exploitation of this source through agricultural irrigation and borehole drilling has caused the lowering of groundwater levels. With climate change, the northwestern region of Bangladesh could face increasing temperature rises, e.g., from 1.3 to $2.6^{\circ} \mathrm{C}$ between 2030 and 2070, respectively, during the winter season [11]. As a result, regionalscale drought risks may increase due to declining water availability [12].

Drought is also increasing social vulnerabilities in Bangladesh, particularly amongst women. Such vulnerabilities specifically relate to what Adger and Kelly describe as the state of individuals, of groups, of communities defined in terms of their ability to cope with and adapt to any external stress placed on their livelihoods and well-being' [13]. Climate change-related drought is increasing such external stresses on citizens and communities in Bangladesh [6]. Between 1980 and 2019, it is estimated that economic loss to drought amounted to $\$ 21$ billion nationally, with approximately 12 million people impacted [7]. Drought particularly affects the economic viability of agricultural systems through reducing water available for irrigation [14]. Lack of water also leads to declining agricultural investments, changed cultivation patterns and crop substitution [15,16]. Other adaptation responses to drought include farmers engaging in short-term migration or undertaking paid off-farm employment, further reducing agricultural activity [6]. Consequently, food insecurity is increased as agricultural production is lost [10]. Health effects can include higher incidences of disease from contaminated water sources when main drinking water supplies become depleted [17]. Other impacts include malnutrition and increased frequency of diarrhea, respiratory and skin diseases, particularly in children [6]. Drought also directly impacts the vulnerability of the poor and particularly poorer rural women in water-stressed areas. Such women disproportionately suffer its consequences due to their dependence on natural resources for their livelihoods and because they are often responsible for water collection and use [17].

While study has been conducted into climate-induced 'gendered vulnerabilities', primarily in response to flood hazards in Bangladesh [18], only limited academic research has examined how drought is impacting gender. Multiple vulnerabilities of Bangladeshi women in relation to climate change more broadly are identified by Tanny and Rahman [19]. They include vulnerabilities to women's health and physical security, food security, access to water resources and work participation, with such climate change impacts mediated through socially constructed gender roles, land ownership differentials and power asymmetries [19]. In their study of how climate change impacts women in Bangladesh, primarily through flooding events, Ferdous and Mallick [18] show how women are highly vulnerable through discrimination resulting from limited access to education, the dowry system and domestic violence. In addition, Naz et al. [20] identify the need for improved land access and literacy for women to enable them to adapt to climate-related flooding. Similar responses for reducing the vulnerabilities of women from flood hazards are identified by Islam [21]. Such findings reflect observations of gender-based vulnerabilities to drought in other national contexts, where women are considered vulnerable through their socioculturally patterned gender roles, established by traditional patriarchal norms and socioeconomic structures [22-26].

These arguments also reflect wider discussions around both the sociocultural construction of climate vulnerabilities and gender-based conceptions of water management. Significant cross-national gaps exist between men and women regarding concern for climate change impacts, due to contextual differences [27]. Moreover, women, particularly in the Global South, are shown to be more vulnerable to climate change than men, through factors such as restricted access to resources, poor housing and their limited participation 
in adaptation governance [28]. Vulnerability from this perspective could therefore be understood 'as a socially-constructed phenomenon influenced by institutional and economic dynamics' [13] and also the nature of climate change impacts. They can also reflect cultural factors: not only does climate change physically threaten the 'cultural dimensions of lives and livelihoods that include the material and lived aspects of culture, identity, community cohesion and sense of place', culture also determines societal adaptation responses [29]. Mutually constituted sociocultural constructions of self and place regarding climate vulnerabilities have consequently been researched in multiple contexts [30]. These arguments, in addition, link to feminist political ecology research showing that 'gendered subjectivities' in water management in Bangladesh are not only socially constructed through pre-existing norms and rights but also reflect the physical characteristics or 'spatiality and materiality' of the water environment [31]. On this basis, the construction of self-identity in relation to place, it is argued, should be better reflected in environmental decision making for achieving sustainability [32], suggesting that gendered vulnerabilities should be a key consideration in adaptation responses. Such features are, however, overlooked in previous studies on gender vulnerabilities in Bangladesh, while - as argued further below-climate adaptation policy in this context often lacks what Brown et al. call 'empathy' [32] toward such constructions. Specific knowledge of drought-related impacts on the sociocultural construction of gender vulnerabilities in Bangladesh is therefore needed to inform emerging policy responses, providing a rationale for further research.

In addressing this gap, this research aims to analyze how drought impacts the vulnerabilities of women in terms of such constructions through sociocultural consideration of self-identity and place in relation to the natural environment. To meet this aim, this paper adopts the following structure. Section 2 outlines the study methods, which are based on an ethnographic case study of a village in Gaibandha district in the northwestern region of Bangladesh, primarily involving focus group discussions. As described above, this region is highly vulnerable to climate change-related droughts, receiving significantly less rainfall than other areas of Bangladesh $[6,9,33]$. Section 3 presents the study results by providing an overview of gendered perspectives on drought-related climate concerns identified by this study. Discussion of these results is provided in Section 4, where a perspective on their implications for policy is presented and our conclusions forwarded.

\section{Materials and Methods}

\subsection{Study Area}

This paper is based on the study entitled Discourse of Community Sustainability in Climate Change Adaptation, undertaken by researchers in the Department of Sociology, University of Dhaka. Previous study of sociocultural dimensions of climate change has typically involved ethnographic, qualitative research [29]. An ethnographic study design was therefore chosen for this research that included focus group discussions (FGDs), used to collect qualitative data from the study area in Badlagaree village, Gaibandha district in Bangladesh. Badlagaree village is situated in the Sadullapur subdistrict of Gaibandha district (see Figure 1), with a geographic area of 228 square kilometers. The total population in this district is 287,426 , with 140,423 male and 147,003 female inhabitants. The study village has 530 households, with an average family size of five and 643 married women aged 18 years and above. Land scarcity has been increasing along with the current population densities, resulting in a major lack of resources for securing decent livelihoods [34]. Agriculture is the main source of employment for 76 percent of villagers; among them, 55 percent of people own cropland and 45 percent are landless [34]. Considering these variables, landless women were the primary target respondents for this study. The major reason for selecting Badlagaree village is that climatic concerns, primarily drought, affect poor people disproportionately in terms of agricultural production, employment opportunities, and violence against women. 


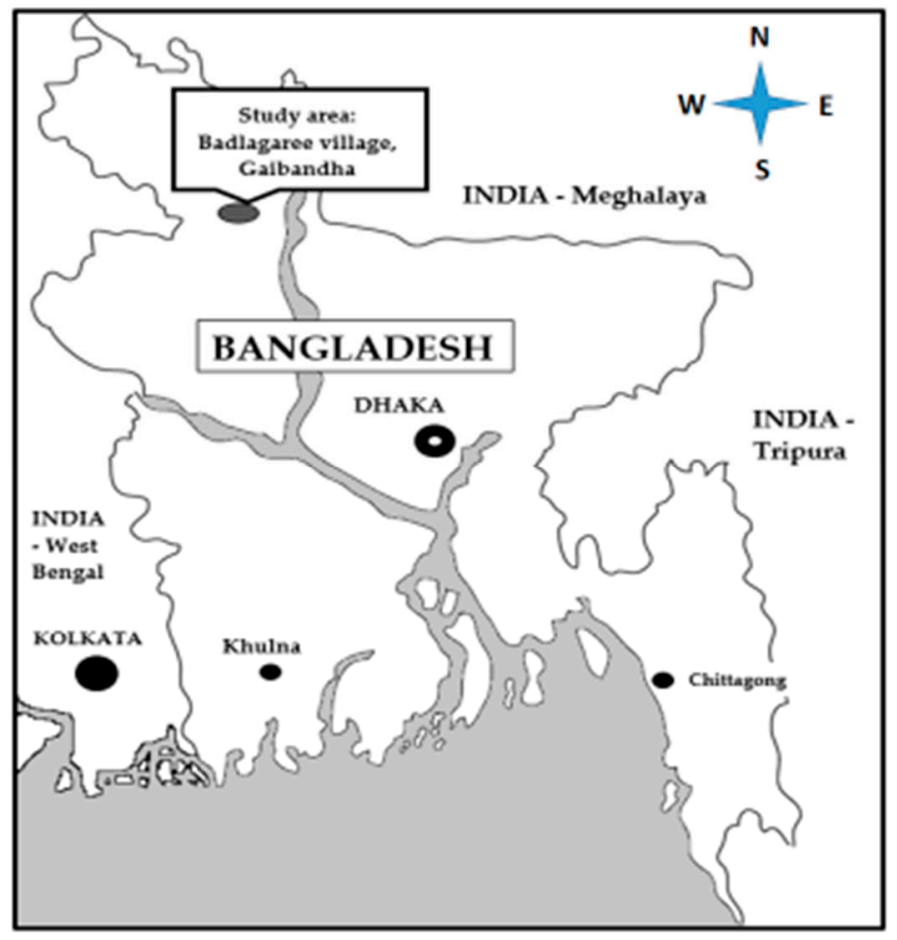

Figure 1. The fieldwork location at Badlagaree in Bangladesh.

\subsection{Data Collection and Analysis}

The fieldwork activities were conducted in 2018, beginning with participant recruitment. The eligible participants of this study were women aged 40 and above living in this village. They have more profound experiences of climatic concerns, have a deeper knowledge on livelihood dynamics, and have typically faced social problems. In total, 47 participants were recruited by Research Assistants of Dhaka University using convenience and snowball sampling. Before collecting any data, the participants were informed about the aims of this study, what it involves and their right to withdraw from this study at anytime without penalty. They were assured that anonymity would be maintained throughout the process of data collection and dissemination of the results. Verbal or written consent was secured to ensure ethical protocols were adhered to. Consequently, FGD participants are anonymized in this study by using respondent numbers to identify participants where discussion data are used in order to ensure their privacy in data analyses. In addition, to ensure transparency and representativeness in the research process, the collected data were verified with the respondents during the data processing and analyses. We shared our findings with the study participants by visiting them in 2020 and incorporated their feedback when finalizing our analysis.

Data collection was primarily focused on the FGDs. Before conducting the FGDs, a short quantitative survey was undertaken with each of the participants comprised of closed questions related to their background including age, employment, education, marital status and socioeconomic conditions. The focus group discussions were then conducted between 15 June and 15 August 2018. Six FGDs, each with 7/8 participants, were conducted to understand the social and cultural dynamics of drought and its effects on gender-based household members. The FGDs were informed by a series of open-ended questions relating to participant's views on six broad aspects: (i) socioeconomic conditions in the village; (ii) climate change conditions, primarily identified as drought; (iii) socioeconomic effects caused by drought; (iv) discrimination against women caused by the socioeconomic effects; (v) current social policy of the government in Bangladesh for ensuring climate change adaptation; and (vi) recommendations for gender-friendly adaptation policy. Data were collected and then transcribed into text form. These transcripts were subjected to discourse 
analysis using conventional qualitative data analysis software (N-Vivo produced by QSR International based in Melbourne Australia) in order to inductively identify key emergent themes from the data from each focus group. The aim was to understand how participants viewed gender vulnerabilities and also potential policy responses to adaptation.

\section{Results: Gendered Perspectives on Climate Concerns}

Results from FGDs were analyzed to identify broad themes emerging from the fieldwork data. These themes relate to the six aspects discussed in the focus groups: socioeconomic conditions; climate change conditions, primarily drought; socioeconomic effects caused by drought; gender-related vulnerabilities; current social policy for climate change adaptation; and recommendations for policy change.

\subsection{Socioeconomic Conditions}

The focus group discussions revealed how low levels of household income increase vulnerability and determined strategies for coping with drought effects. In Gaibandha district, the population density is 1125 per square kilometer, with a family size of 3.88 and a literacy rate of 42.81 (see Table 1), indicating the drought resilience conditions in the locality [35,36]. Agricultural activities are the main mode of livelihood; 87 percent are small-farm holders who own cropland between 0.05 and 2.49 acres and one percent own cropland more than 7.50 acres, termed as large farm-holders. In the lower socioeconomic strata, the family size is larger, and the literacy rate is lower, which causes further pressure on coping with drought effects. The focus group discussions revealed that one earning household member with a daily wage of Bangladesh Taka 300 cannot easily provide food, education, health care, housing, and clothing for their family. Unemployment or poorly paid work makes the socioeconomic conditions of families even more vulnerable. Smallfarm holders cannot cope with minor drought effects such as agricultural production loss. They then encounter significant livelihood vulnerabilities such as unemployment, while large-farm holders are more successful in coping with these effects.

Table 1. Socioeconomic characteristics important for livelihood activities in Gaibandha. Source [35,36].

\begin{tabular}{|c|c|c|c|}
\hline Category & \multicolumn{2}{|c|}{ Attributes } & Total \\
\hline \multirow{4}{*}{ Population } & \multicolumn{2}{|c|}{ Per square kilometer [35] } & 1125 \\
\hline & \multicolumn{2}{|c|}{ Family size [36] } & 3.88 \\
\hline & \multicolumn{2}{|c|}{ Sex ratio (male/female) [36] } & 97 \\
\hline & \multicolumn{2}{|c|}{ Literacy rate [35] } & 42.81 \\
\hline \multirow{3}{*}{ Farm Holding [36] } & \multicolumn{2}{|c|}{ Total number of farm holdings } & 326,770 \\
\hline & \multicolumn{2}{|c|}{ Small } & 285,172 \\
\hline & \multicolumn{2}{|c|}{ Large } & 3480 \\
\hline \multirow{6}{*}{ Irrigation [36] } & \multirow{2}{*}{ Paddy } & Total & 504,941 \\
\hline & & Irrigated & 303,022 \\
\hline & \multirow{2}{*}{ Wheat } & Total & 5402 \\
\hline & & Irrigated & 5402 \\
\hline & \multirow{2}{*}{ Potato } & Total & 22,602 \\
\hline & & Irrigated & 22,602 \\
\hline \multirow{6}{*}{ Crop production [36] } & \multirow{2}{*}{ Aus } & Local & 2464 \\
\hline & & HYV & 5577 \\
\hline & \multirow{2}{*}{ Aman } & Local & 92,554 \\
\hline & & HYV & 153,819 \\
\hline & \multirow{2}{*}{ Boro } & Local & 33,514 \\
\hline & & HYV & 101,003 \\
\hline
\end{tabular}




\subsection{Drought Conditions}

The impacts of drought were also discussed in the focus groups. When asked 'How do you understand drought as a component of climate change?', FGD Participant 01 stated that: "we do not understand climate change; we describe it as relatively hot temperatures, irregular or lesser seasonal rainfall, and dry ponds." Echoing Participant 01, another respondent (Participant 07) described how:

"drought effects our livelihoods through an extreme level of dehydration: [we] do not get enough drinking water, and cannot work outside or escape the heat shock by taking refuge at a pond side or tree shelter. Due to the failure of seasonal water flows, we encounter major challenges for cooking, domestic animal nurturing, and wild fish availability in ponds and local common pool water bodies."

When asked about the environmental aspects of drought with the question, 'how do you evaluate the environmental effects caused by droughts?', Respondent 01 described them as "lower rainfall, no water in the river, ponds, and wetlands, soil fertility loss, death of fruit trees like mangos, and loss of wild vegetation increasing day by day." Participants experienced hot or cold weather in an irregular seasonal context, which had increased in recent decades. Drought is currently persistent, and there is a longer winter occurring regionally, which impacted all FGD participants. One main reason for this drought, according to participants, is lower levels of rainfall or irregularity of rain during the rainy season. The frequency of drought is also increasing in this area, occurring between November and February every year. Participant 07 stated that higher levels of heat were causing loss of agricultural production and livelihood opportunities. This level of drought is also leading to loss of human life and livestock, which increases due to the water crisis.

The FGDs also helped identify how drought causes major challenges for agricultural activities, as water resources and irrigation facilities are an important component for highyielding variety (HYV) crops, as identified in Table 1. In Gaibandha, major winter crops such as wheat and potatoes rely on irrigation. Moreover, the rice paddy fields of HYV aus, aman, and boro also need irrigated systems. Drought conditions therefore cause major harm to all of these staple food crops. Agricultural activities in Gaibandha district are also more vulnerable to drought effects; small-scale farmers, who have cropland of less than 2.5 acres, encounter major livelihood vulnerabilities.

\subsection{Socioeconomic Effects of Drought}

The FGD responses showed that drought effects are currently the major challenges for social sustainability in relation to agricultural production, food security, drinking water provision, domestic livestock rearing, employment and work-related safety within the study area. Discrimination against women is discussed further in Section 3.4.

Agricultural production in rural areas is climate sensitive and largely depends on the seasonal patterns of the ecosystem. The uncertainties associated with this ecosystem in terms of low rainfall, water shortages or lack of access to water causes livelihood issues in terms of damage to agricultural production. This observation reflects the findings of Hoffman, who argues that environmental problems can cause significant effects on society [37]. Local poor people are increasingly concerned about their agricultural practices because with intensifying levels of drought, they cannot use their ecological knowledge of past drought patterns. Cropland becomes infertile and turns into desert due to continuous drought effects, leading to agricultural uncertainty and falling production, which is harmful to all the Badlagaree villagers. Those involved in agricultural activities are directly affected by the drought, while those dependent on agricultural production, such as blacksmiths, encounter their loss indirectly through lack of business.

Water scarcity caused by drought has also increased livelihood challenges related to access to food. Due to drought, respondents failed to produce enough crops and hence ensure their household food security. Crop production effects were not limited to the winter season; they extended into the next season, with jute and sugarcane production also severely hampered by drought. 
The villagers in Badlagaree also encounter drinking water vulnerabilities as a result of drought. Participants 01 and 20, for example, could not afford to buy their own tubewell or access one owned by a neighboring wealthier household. Some people, such as Participant 31, managed to obtain a bucket of water in exchange for filling two buckets for the tube-well owner. A lack of safe water is also responsible for water-borne diseases such as diarrhea or related health problems, as encountered by Participants 01 and 20 and their household members.

Participant 20 informed us that domestic animals also encounter fodder scarcity, heatwave-related diseases and death due to drought exposure. Because of extreme drought conditions, the village area lacks any wild vegetation for fodder. This resource is essential in keeping locals healthy and a major source of family income, agricultural production, and household nutrition. The decline in fodder availability has reduced domestic animal nurturing and created a debt trap for poor people. For example, another participant bought two goats with a microcredit loan as an investment. She expected to sell them during Eid-ul-Adha, the yearly Muslim religious celebration. One goat was undernourished due to the fodder crisis, and she bought it at a low price. However, the goat died within three months due to diarrhea linked to the heatwave. In the meantime, she faced pressure from paying the microcredit instalments. Finding no other alternatives, she sold the other goat and repaid 60 percent of the loan. Now she works as a maid servant in a wealthy farmer's household and pays the remaining instalments to service the loan. Other participants encountered extreme levels of economic distress and livelihood challenges due to impacts on their domestic animals.

The resulting lower level of agricultural production is reflected in declining employment opportunities and income. Agricultural activities are the main sources of employment opportunities, which are only possible when seasonal climate patterns are reliable. However, the increasing unpredictability of the climate has caused a significant loss of agricultural production. Participant 07 argued that it is responsible for higher levels of unemployment. When asked about local mechanisms in overcoming such drought concerns, with the question 'what types of measures do you take to overcome the drought effects?', another participant stated:

"we work in a rice processing mill, road construction, or a household of rich peo-

ple. However, most of us encounter low wages, exploitation, discrimination, and sexual harassment."

Local people encounter major unemployment when this region endures extreme levels of drought. As a result, only 10 percent of women FGD participants could secure permanent employment, while 50 percent had temporary employment, and the remaining 40 percent encountered unemployment. Some women work in rich people's households or in small factories such as a rice mill. Some village males work as rickshaw pullers. Participant 41 stated that when poor people fail to secure a job locally, they search for opportunities elsewhere by migrating to other districts including Manikgonj and Sylhet to work as agricultural laborers on a seasonal basis.

The initial survey data identified that 44 percent of the respondents had undertaken unsafe employment as machine operators in rice mills, road construction workers, helpers in buses or trucks, or building construction workers. According to our FGD and participant observation data, these workers operate mill machinery without any safety gear. Participant 29 described how as a result some workers lose parts of their body such as a finger from accidents. Neither the mill owner nor government provides them with health care or future livelihood support. Participant 20 also described how helpers in buses or trucks perform their tasks with extreme risk; they sometimes hold onto the outside of vehicles running at high speed. Building construction workers face similar risks; many die in work-related accidents or are permanently injured. Thus, those impacted have double vulnerabilities: permanent physical disability and poverty. In addition to these vulnerabilities, many locals have encountered physical harassment, such as beatings by their employers for making a 
mistake. Poverty caused by drought effects is increasingly responsible for these modern slavery conditions.

Other groups do not have the scope for accessing even these types of employment opportunities or special employment programs suitable for them. Here, older people, widows and young mothers have less choice in job opportunities. According to Participant 12 , disabled people encounter the very worst employment conditions: younger people receive only their daily meals in exchange for a whole day's work, while older people typically receive even lower daily wages than their younger counterparts.

Because of drought effects, 46 percent of the survey respondents and their family members encountered unemployment and related suffering. Many migrated searching for employment opportunities such as agricultural work or rickshaw pulling, thereby experiencing extreme vulnerabilities. Husbands or male members are the breadwinners of households in the Gaibhnada district. At the same time, their female counterparts are responsible for domestic tasks, as communicated to us during the FGDs. Among the survey participants, 30 percent reported that their husband works as a day laborer who earns on average BDT 4700 every month. Other people earn less; 16 percent of the survey respondents informed us that their husband makes approximately BDT 4000. This earning level is even less, BDT 3200, for 21 percent of the respondents. This income level is not enough to maintain households, consisting of an average of five members in Badlagaree village, as it only ensures the minimum food availability to household members. Other needs such as access to education or health care are grossly unrecognized in this culture of poverty. One participant (20) faced back pain for a long time; she cannot stand up for undertaking nominal household chores. Ten years ago, she visited a doctor when a health campaign was organized by the Red Crescent Society. The doctor provided medicines and prescribed food essential to recover from the health problem. Afterwards, she failed to continue her medication or buy food due to ongoing financial hardship. The drought problem made her livelihood more vulnerable as she was unable to earn money or nurture domestic animals for supplementing the household income.

\subsection{Gender-Related Vulnerabilities}

The FGDs revealed significant gender-related vulnerabilities of drought in terms of unequal wages, unsafe working conditions, violence, access to food, limited education and inequalities stemming from the patriarchal system.

Related to unequal access to employment opportunities is widespread discrimination in wages for paid work. Fifty percent of the survey female participants received a lower wage than their male counterparts. In Badlagaree village, one FGD participant informed us that a male worker typically receives BDT 300 daily, whereas a woman laborer receives only 120 for the same tasks. Therefore, limited job opportunities and wage discrimination combine to create major challenges for climate change adaptation, which deteriorate further with gender-based exploitation.

Significant numbers of women work in mills and factories to maintain a decent livelihood but suffer poor conditions. Responding to the question 'how do you consider the working environment at a local factory in terms of gender friendly sanitary facilities and respect to women?', Participant 43 described how "woman laborers in most of the workplaces do not have separate toilet facilities, and this lack of sanitation facility increases health problems, violence, and shame." Sometimes women fail to raise their voices over such concerns due to fear of losing their job. If this happens, their family will suffer from lack of food and nutrition, access to education and health care, and housing. This necessity is imposed by the loss of agricultural production or related concerns caused by poverty and unemployment.

Social stigmatization is another major reason for women's vulnerabilities that goes mostly unrecognized due to poverty. One participant (31) elaborated on workplace violence in responding to a question, "why do most women not protest against the violence they encounter in the work place?' by saying that: 
"women who are raped or are victims of sexual abuse by a factory owner or fellow worker are not accepted by their husbands nor in-laws or villagers due to the concept of purity imposed by local beliefs and practices. They are labelled as 'bad women' who lose their social acceptability in their community."

When questioned further about violence against women, Participant 31 described the linkage with unemployment caused by climatic concerns. Their point is similar to Barnett and Adger [38], as they argued that resource scarcity increases resource competition, which in turn is responsible for social problems. Due to the increasing economic crisis combined with sickness or loss of the main household breadwinner, anxiety and depression have increased in Badlagaree village. Among the initial survey respondents, 77 percent encountered economic insecurity, which is additionally increasing violence against women. From the FGDs, physical violence is described as kicking, shaking, pushing, pinching, hitting and beating for a minor issue such as delays in serving meals or even failing to give birth to a son. Perpetrators use different objects to harm women, such as sticks or their hands. Mental torture involves verbal abuse or psychological violence. Unfortunately, most women face this violence; FGD participants argued that higher levels of drought effects were causing higher levels of violence against women. In addition to this socioecological effect, violence is promoted as part of the patriarchy. It is used to preserve social order and secure the privileged under the social framework of patriarchy by maintaining its control over resources. This tradition is becoming further entrenched due to increasing climate vulnerabilities and related poverty.

Women in poverty socialize their female children to show deep respect for their potential husband through generational learning. Parents and grandparents socialize them to respect such patriarchy in order to secure a wife's socioeconomic status and avoid further vulnerabilities caused by drought. During the FGD data collection, one respondent, Participant 20, stated that a "wife's haven is under the feet of husband". This socialization perspective regarding respect for patriarchy was echoed by other FGD respondents, although some maintained silence during the discussions. One major reason for supporting this patriarchy is the lack of access to education caused by poverty; a socioeconomic condition that has further deteriorated due to drought.

Drought effects cause damage and loss to food production and resultant food price increases, creating unequal access to food and nutrition. During our FGD, Participant 20 informed us in response to the question, 'what types of food access concerns do you face due to drought?':

"drought causes an extreme level of food crisis due to failures of crop production, vegetation loss, and declining wild fish."

She sometimes ate only once daily because of these climate change effects. The only available food was of low quality, such as traditional bread called roti, partly rotten rice called pantha vat, or watered rive or jao. She searched for wild leaves and vegetables, exchanged employment for food and scavenged dumped food from hotels or restaurants.

Regarding food access, women are most vulnerable during drought; 88 percent of the survey respondents encountered this inequality. Participants 20 and 31 experienced having food only once a day or just eating bread. Some participants starved for a day or more to ensure food for breadwinning male members of their household. Only 22 percent of the survey respondents could obtain the minimum food needed for their everyday activities. Whatever happened to their access to food due to climate change effects, 79 percent of married female survey participants tried to provide the maximum amount of food to their husbands. Their logic is that the husband performs the hard work, and without obtaining enough food, they could not perform their tasks correctly, resulting in employment termination.

Drought effects linked to failures of effective adaptation programs are responsible for many of these problems, which also impact other rights such as access to education. Due to climate change vulnerabilities, 43 percent of the survey respondents failed to receive formal education and could not read and write. Low levels of female education are the 
foundation of gender-based socialization in Badlagaree village. When asked about the reasons for limited education for female children, Participant 31 informed us:

"Early marriage requires lesser dowry, reducing the scope for girls education. Although the government scholarship for primary education is helpful for ensuring their right to primary education, they cannot afford the education for the next level like secondary or higher. The government provides scholarships for education but many parents cannot afford other costs: e.g., food, clothes, transportation. Eve teasing on the way to school or sexual harassment causes further challenges, and an older wife is less docile and not helpful for family peace and stability."

Traditionally, parents focus less on their daughter's education due to the local division of labor. In this context, Participant 20 stated that "women are supposed to perform household tasks that do not need a higher degree, but sons need to go outside and earn money for taking responsibility for the whole family." In addition to this traditional belief, travel between home and school causes another major barrier in educating girls due to personal security concerns. Among the survey respondents with children in school, 80 percent send their male children to school, while only 20 percent send both male and female children. The highest level of education is Higher Secondary Certificate, which is accessed only by 1.4 percent of villagers.

Early marriage and dowry are widely practiced social challenges in Badlagaree village. Among the survey respondents, 20 percent had encountered child marriage, although the real number is undoubtedly higher, as argued by FGD participants. Many participants did not know the minimum age of marriage. Some people have to ask school teachers or Non-Government Organization (NGO) activists about the minimum age of marriage when they consider searching for a potential husband for their daughter. Sometimes they hide their daughter's age from outsiders to receive a good marriage proposal.

Poverty forces local poor people to accept early marriage in coping with climatic vulnerabilities. Due to drought effects, they would like to reduce household food expenditure and secure their daughter's future. In this context, access to education creates new economic and social problems responsible for lower levels of school enrolment or graduation. FGD Participant 01 made a more concerning point that the demand for a literate bride is actually lower in the locality, as they are believed to potentially demonstrate disloyalty to their husband, challenge their husband's decisions, and sometimes engage in conflict that undermines family peace and stability. Moreover, early marriage requires a lower dowry, which is helpful for poor people, especially in the context of climatic vulnerabilities. Currently, drought-vulnerable poor people are more concerned about their daughter's marriage. One participant described how she worried that her daughter is eyburo, a Bengali word meaning an older girl without an expected groom, as this decreases the chances of securing a better marriage. The economic scarcity experienced by poor people, caused by drought effects, makes them more vulnerable to believing in this culture of early marriage.

According to FGD participants, poverty forces them to endure social problems caused by rich or influential persons. Sometimes an influential person can force a droughtvulnerable poor parent or girl to accept a groom who lost his wife or has divorced. Others are more vulnerable; sometimes, younger women can become the second or third wife of wealthier men in the hope of getting daily food and avoiding starvation in their parents home. Other girls encounter violence such as rape or other physical harassment and fail to receive social recognition or legal support in protecting their rights. Poverty caused by drought effects and related vulnerabilities is the major socioecological reason for this social problem.

A dowry system is also prevalent in Badlagaree village. Among the survey respondents, 67 percent provided a dowry for their daughter's marriage. They provided different types of dowry including fridges, gold, money, furniture, animals, watches, cycles, or motorbikes as gifts to the groom and their family. Among the types of dowry, 40 percent of the survey participants gave only money, while 18 percent gave money, gold, furniture, and domestic animals. The dowry can have a time dimension depending on the informal agreement between the two families, with items provided before, during, or after the 
marriage. Despite their vulnerable economic condition, they offer the dowry to ensure their daughter's future well-being. Sometimes, they take out a microcredit loan to provide the dowry. Microcredit agencies and the government therefore need to examine this practice when considering the effectiveness of climate change adaptation.

A dowry is currently a dominant pattern of social business practiced by local poor people as they try to maximize their profit in the marriage market. In this context, they use microcredit loans; the person facing extreme financial challenges in offering a dowry as a parent of a daughter also creates similar social pressure for another family when they are the parent of a son. This is a complex pattern of maximizing economic gain and trying to improve socioeconomic conditions. According to Participant 07, the total dowry depends on socioeconomic status and the bargaining strategy. When a family secures a better groom in terms of educational qualifications and wealth, the daughter's parents offer a higher dowry. The level of dowry depends on the background of the girl, the parents socioeconomic status in terms of jobs and assets, the grandfather's status, and the total number of siblings. When the parents have a better job or assets, the dowry is not a forcing issue; it turns into a willingness issue or a symbol of prestige. Alternatively, when a family has a better network for securing a new job or solving social problems, the dowry becomes less important.

Despite having this social business perspective, the dowry has become a great financial burden among the families of brides when poor parents encounter sudden loss of crops or other assets caused by drought effects, as argued by one FGD participant. Many sell their remaining assets cheaply to provide this dowry when they fail to access a microcredit loan. When the parents cannot provide the agreed dowry, it causes multiple social problems to the bride: they can face divorce or physical and emotional violence including insults, ridicule, and humiliation. The husband is mainly responsible for this but it is also sometimes caused by parents or relatives of the husband. Physical violence sometimes continues until the wife can bring the money, leaves the husband's house, or commits suicide. The husband sometimes marries a new girl to secure the targeted dowry. Pressure to gain more money than the agreed dowry also comes when the husband encounters damage and loss of investments due to drought effects.

\subsection{Current Social Policy}

Appropriate social development programs for adaptation are key to ensuring longterm sustainability in accessing employment opportunities, challenging patriarchy, and gaining individual dignity in community life: a feature discussed in the FGDs.

The government has some specific programs promoting the sustainability of local people against climatic concerns. Based on our questioning regarding these programs, 70 percent of survey participants received no support. The remaining 30 percent had government help with education for female children and domestic animal nurturing, plus maternal, widow or elderly support. In reality, these supports failed to meet their minimum needs, as stated by FGD participants.

The government has other related programs such as the Food for Work and Employment Generation Program for the Poorest (EGPP), which are promoted alongside industrial development programs such as the Export Processing Zone and agricultural development technologies such as high-yielding variety (HYV) crop production and intensification. Based on these policies, the government aims to create significant employment opportunities for women through social change and adaptation. Here, the government's social development programs are framed in terms of Gross Domestic Product (GDP) and an economic growth perspective but they have had only limited effect in the village. FGD participants described how young females and unmarried people are prioritized in job opportunities while other groups, including older women, are largely unrecognized in accessing employment.

Government policies have also emphasized agricultural modernization and industrial development as the major source of employment opportunity and climate change adapta- 
tion. However, development programs such as road construction, industrial park creation, economic zone establishment and housing projects produce a greater demand for scarce cropland; when the owners are poor, it creates major concerns over their livelihoods. In this context, it is important to understand the reasons for growing displacement of poorer people linked to major development programs such as economic zones. In response, FGD Participant 01 argued that development project decision making is dominated by influential people regarding site selection, construction activities and rehabilitation, and therefore should protect human rights and promote social justice. Social development programs should also offer specific programs for rehabilitating marginalized people who gain little from new development activities due to their socioeconomic situation, e.g., age, gender, marital status, and literacy status. Some older people, for example, do not have the literacy skills to benefit from modernization development activities. It therefore becomes important to bridge economic and social development to ensure the sustainability of climate-affected people, as argued by Brown regarding adaptation approaches [39].

Policies also support adoption of agricultural technologies such as high-yielding variety crops but again they only benefit specific groups. Participant 31 stated that wealthy farmers are invariably the primary beneficiaries of these subsidized technologies, which fail to create positive effects for climate change adaptation. Due to this technological innovation, FGD Participants 20 and 31 argued that local employment opportunities have been decreasing in Bangladesh in two ways: (i) accessibility to subsidized technologies and (ii) affordability. They stated that:

"We live by undertaking traditional activities like agricultural production and fishing; many of us do not have the minimum literacy to cope with new technologies which causes increasing concerns over unemployment. Again, we cannot afford these technologies and production materials due to our limited assets or capital. An NGO loan for purchasing this equipment is not suitable due to its complex instalment approach in returning the capital and its associated interest."

The linkage between the local community and natural environment has developed for generations within traditional agriculture: a relationship under threat from current policies. This linkage is helpful for both local people, biodiversity, and ecosystems. During her early years, one FGD participant collected livelihood resources from the local environment, including the wetland, which allows harvesting of more than two crops a year and is very fertile for agricultural production. The government therefore needs to protect every component of biodiversity and ecosystems to ensure a healthy environment and sustainability, which can help marginalized groups undertake climate change adaptation.

Finally, local livelihood transformation from traditional agricultural practices to industrial agricultural causes additional concerns for poorer women. In the past, one FGD participant and her husband produced crops with traditional equipment and maintained an agriculture-based livelihood. They used local knowledge and agro-ecological systems helpful for maintaining community livelihood, also sharing their resources such as share cropping, fruit from their orchard and fish from the pond as part of community belongingness and caring for marginalized people. They had a traditional division of labor, where women perform household tasks while men undertake agricultural work, which has been transforming because of increasing industrial agriculture. Because of this transformation agenda, they faced steep challenges in maintaining their traditional ways of living. Riverbank erosion caused the loss of their last piece of cropland and residential facilities. Thus, they currently live on the streets and lack their human rights and social justice. The transformation from local to global dynamics of agricultural production needs to be dealt with efficiently so that poor people can protect their livelihoods.

\subsection{Recommendations for Gender-Friendly Adaptation Policy}

Several recommendations for adaptation policy can therefore be made to reflect gendered vulnerabilities linked to drought. Women, as identified above, are major victims of the current development-led policy perspective, increasing their climate vulnerabilities 
and social inequalities. A new policy approach can overcome this situation by ensuring their wider inclusion in social and economic program decision making so that they can promote their personal development, which is then helpful for overcoming climate change concerns. Subsequently, this sustainability perspective will help improve agricultural production, create employment and income opportunities, reduce food insecurity, improve access to education, and increase the age of marriage.

This perspective, on the basis of our research, also needs to focus on the multidimensional identities of women rather than the ongoing uniform perception of women as a general category. These multidimensional identities include reference to age, educational level, disability type, economic variability, geographical location, and resource availability. It is important to recognize these aspects when considering involving women in climate change adaptation programs, thereby supporting the arguments of Adger et al. for greater community-wide involvement in adaptation decisions [29].

Related to climate change adaptation, the government also needs more data regarding vulnerable groups, including women, to inform decision making, as Hoffman [37] argues. In this context, information gathering on these groups needs to better recognize employment issues. Currently, there is a significant gap between employment opportunities and unemployment prevalence. For example, one FGD participant, who is both physically disabled and unemployed, argued that government programs such as EGPP fail to employ enough marginalized people. Although the private sector contributes more in fulfilling local demand, it is insufficient in creating decent employment opportunities for marginalized people, including some women.

Social development programs additionally must include mechanisms related to technological justice in order to empower poorer women and the poor generally. Technology must be made available to such groups for promoting their agricultural productive capacities, based on culture-specific understandings of adaptation policy, as argued by Stringer et al. [40]. Such program mechanisms should consequently restrict wealthy farmers from accessing subsidized technologies such as high-yielding variety (HYV) crops. These concerns should be reflected in social development programs so that local people secure increasing employment opportunities based on such new technologies.

The FGDs also identified that social development programs need to generate alternative sources of income when wetlands disappear within the built environment. Women but also the poor and disabled, who are supported by community livelihoods, must be protected in such programs. According to FGD Participant 12, the latter group needs special support from the government and NGOs in maintaining their rights and well-being in this changing environment. They are supposed to receive priority services from the health care system, have the opportunity to obtain a scholarship for higher education and be given job opportunities on a priority basis, depending on their level of education. Otherwise, displaced people and tokai or street children can be a major concern if planners fail to ensure proper compensation or social service programs do not consider their needs.

Finally, the importance of valuing common-pool resources in development project planning processes can be helpful for securing the livelihoods of poorer people, including women, who live in the floodplain area, collecting fish for family nutrition, undertaking employment, or performing sharecropping inside the proposed project site. For those who are displaced by such development, such valuations in relation to loss of employment or food production can inform proper compensation from developers. A valuation approach for ecosystems [41] should also be included in government development policy making, to increase the wider socioeconomic capabilities of all marginalized groups.

\section{Discussion and Conclusions}

This study aimed to understand how drought influences the sociocultural construction of gender vulnerabilities in Bangladesh as a basis for informing adaptation policy. In this respect, although only based on one in-depth case study, the research nonetheless shows that drought is increasing such vulnerabilities under climate change and that 
their construction is mediated through intervening socioeconomic factors and natural environmental conditions.

Women in Bangladesh are subject to multiple vulnerabilities related to drought. As identified above, they include unequal wages and access to employment, unsafe employment, domestic violence, food insecurity, inequitable access to education and discrimination via the dowry system. Many of these vulnerabilities are pre-existing and while not specifically caused by drought are nonetheless being magnified by its environmental impacts due to embedded social and cultural practices, reflecting arguments that context matters in how gendered vulnerabilities are constructed and reproduced [31]. Here, social constructions of self and place [30,32] are not only significant in developing gendered climate vulnerabilities but also adaptation responses. In particular, the mutually constituted 'gendered subjectivities' of drought do reflect both embedded sociocultural determinants and their interaction with the 'spatiality and materiality' of water resources [31], while additionally supporting wider feminist political ecology arguments on the factors influencing gender relations in water management [42].

These findings also reflect those of pre-existing studies, for example Tanny and Rahman's [19] review of the literature on gender-related vulnerabilities of women, showing that they relate to the gendered roles of women in society, particularly regarding access to resources. Ferdous and Mallick [18] also argue that 'discriminatory social norms and practices' increase gender vulnerabilities in Bangladesh through restricting women's mobility and choices. Islam [21] additionally refers to 'Women's physical vulnerability, low level of education, liability to family ... and lack of awareness' in increasing their vulnerabilities during flooding. These aspects are certainly evident in the FGD responses described above. As with floods, drought causes physical uncertainties in the form of low rainfall, shortage of water and seasonal irregularities, leading to livelihood impacts. These effects present women with complex challenges. For example, when agricultural production is lost, they disproportionately feel the impacts through unemployment. They then fail to receive the minimum economic support for their social development, creating further inter-related vulnerabilities. Families, as a result, are incentivized to offer their daughters for early marriage rather than sending them to school, with dowry becoming another significant social problem. Furthermore, women and female children are traditionally considered subordinate to men in the family and society: early marriage helps maintain this patriarchal social order under environmental stress. Greater unemployment has also created dehumanizing working environments as competition for jobs has intensified under drought conditions.

The FGD discussions show that participants perceive adaptation responses in social development programs as lacking 'empathy' in addressing this sociocultural construction of gender vulnerabilities. Cannon and Müller-Mahn, for example, argue that a sustainability perspective requires locally embedded understandings of development [43]. In this respect, sociocultural factors should, as Adger et al. argue, be integrated into adaptation decisions [29]; see also [44]. A greater emphasis on gender perspectives within disaster management policies in Bangladesh has been previously recommended by researchers [45]. However, social development programs, aimed at long-term adaptation, were viewed by FGD participants as particularly needing a special focus on marginalized people, primarily although not exclusively women, during the transition phase between promoting agricultural and industrial sector-dependent livelihoods. Developing such gender-appropriate programs can involve the equitable participation of government, NGO and community actors, i.e., collaborative governance [46,47]. A variety of participatory mechanisms already exist to facilitate such collaboration in governing climate adaptation, for example $[48,49]$. Multi-sector, multi-actor engagement can also support more resilient responses to drought management in agriculture through enhancing human and social capital [50].

Further research is, however, required into how sociocultural constructions shape gendered vulnerabilities in response to drought in Bangladesh and elsewhere. Climateinduced drought is predicted to increase in the coming decades and the priority will be 
designing adaptation strategies that better reflect gender vulnerabilities. Findings of this study suggest a need for further investigation into how both men and women construct their responses within specific sociocultural contexts or 'places' and, critically, how these constructions can empathetically inform greater sustainability in public policy design. That said, this study only sheds light on one village case study, necessitating much wider data collection and analysis. A productive way forward therefore is in undertaking a broad national-scale study, employing quantitative methods to measure levels of gendered vulnerability and women's quality of life under increasing climate change induced drought conditions, in order to shape future adaptation policy in Bangladesh and other national contexts.

Author Contributions: M.A.H., D.B., S.Z.H., Z.S. and M.M.R. contributed substantially to prepare this manuscript. Conceptualization, M.A.H. and Z.S.; Methodology, M.A.H.; Software, M.A.H. and Z.S.; Validation, D.B., M.A.H., S.Z.H. and Z.S.; Formal Analysis, M.A.H., S.Z.H. and D.B.; Investigation, Z.S.; Resources, M.A.H. and Z.S.; Data Curation, M.A.H., M.M.R. and Z.S.; WritingOriginal Draft Preparation, M.A.H., M.M.R. and Z.S.; Writing-Review and Editing, D.B., M.A.H., M.M.R., S.Z.H. and Z.S.; Visualization, M.A.H.; Supervision, M.A.H.; Project Administration, M.A.H.; Fund Acquisition, M.A.H. and Z.S. All authors have read and agreed to the published version of the manuscript.

Funding: This research received no external funding.

Institutional Review Board Statement: Not applicable.

Informed Consent Statement: Not applicable.

Data Availability Statement: No applicable.

Conflicts of Interest: The authors declare no conflict of interest.

\section{References}

1. IPCC. Climate Change 2001: Impacts, Adaptation and Vulnerability; McCarthy, J.J., Canziani, O.F., Leary, N.A., Dokken, D.J., White, K.S., Eds.; Cambridge University Press: Cambridge, UK, 2001.

2. Ford, J.D.; Pearce, T.; McDowell, G.; Berrang-Ford, L.; Sayles, J.S.; Belfer, E. Vulnerability and its discontents: The past, present, and future of climate change vulnerability research. Clim. Chang. 2018, 151, 189-203. [CrossRef]

3. Li, M.-H.; Tseng, K.-J.; Tung, C.-P.; Shih, D.-S.; Liu, T.-M. Assessing water resources vulnerability and resilience of southern Taiwan to climate change. Terr. Atmos. Ocean. Sci. 2017, 28, 67-81. [CrossRef]

4. Hossen, M.A.; Chowdhury, M.A.; Asha, H.; Tagoe, C.A.; Allan, A.; Nelson, W.; Patel, A.; Mondal, M.S.; Salehin, M.; Quaye, R.M.; et al. Governance Challenges in Addressing Climatic Concerns in Coastal Asia and Africa. Sustainability 2019, 11, 2148. [CrossRef]

5. Displacement Solutions. Climate Displacement in Bangladesh: The Need for Urgent Housing, Land and Property (HLP) Rights Solutions; Displacement Solutions: Geneva, Switzerland, 2012.

6. Goosen, H.; Hasan, T.; Saha, S.K.; Rezwana, N.; Rahman, R.; Assaduzzaman, M.; Kabir, A.; Dubois, G.; Terwisscha van Scheltinga, C. Nationwide Climate Vulnerability Assessment in Bangladesh; Ministry of Environment, Forest and Climate Change and GIZ: Dhaka, Bangladesh, 2018.

7. Salam, R.; Islam, A.R.M.T.; Shill, B.K.; Monirul Alam, G.M.; Hasanuzzaman, M.; Morshadul Hasan, M.; Ibrahim, S.M.; Shouse, R.C. Nexus between vulnerability and adaptive capacity of drought-prone rural households in northern Bangladesh. Nat. Hazards 2021, 106, 509-527. [CrossRef]

8. Hossain, M.N.; Chowdhury, S.; Paul, S.K. Farmer-level adaptation to climate change and agricultural drought: Empirical evidences from the Barind region of Bangladesh. Nat. Hazards 2016, 83, 1007-1026. [CrossRef]

9. Islam, A.R.M.T.; Shen, S.; Hu, Z.; Rahman, M.A. Drought Hazard Evaluation in Boro Paddy Cultivated Areas of Western Bangladesh at Current and Future Climate change Conditions. Adv. Meteorol. 2017, 1-12. [CrossRef]

10. Hoque, M.A.A.; Pradhan, B.; Ahmed, N. Assessing drought vulnerability using geospatial techniques in northwestern part of Bangladesh. Sci. Total Environ. 2020, 705, 1-13. [CrossRef]

11. Mallick, D.; Hossain, Z. Climate Change, Food Security and Our Vulnerability; Daily Star: Dhaka, Bangladesh, 2019.

12. Kirby, J.M.; Mainuddin, M.; Mpelasoka, F.; Ahmad, M.D.; Palash, W.; Quadir, M.E.; Shah-Newaz, S.M.; Hossain, M.M. The impact of climate change on regional water balances in Bangladesh. Clim. Chang. 2016, 135, 481-491. [CrossRef]

13. Adger, W.N.; Kelly, P.M. Social Vulnerability to Climate Change and the Architecture of Entitlements. Mitig. Adapt. Strateg. Glob. Chang. 1999, 4, 253-266. [CrossRef] 
14. Xenarios, S.; Nemes, A.; Sarker, G.M. Assessing vulnerability to climate change: Are communities in flood-prone areas in Bangladesh more vulnerable than those in drought-prone areas? Water Resour. Rural Dev. 2016, 7, 1-19. [CrossRef]

15. Ahmed, B.; Kelman, I.; Kamruzzaman, M.; Mohiuddin, H.; Rahman, M.M.; Das, A.; Fordham, M.; Shamsudduha, M. Indigenous people's responses to drought in northwest Bangladesh. Environ. Dev. 2019, 29, 55-56. [CrossRef]

16. Kabir, M.J.; Alauddin, M.; Crimp, S. Farm-level adaptation to climate change in Bangladesh: An analysis of adaptation dynamics, profitability and risks. Land Use Policy 2017, 64, 212-264. [CrossRef]

17. Rahman, M.M.; Ahmad, S.; Mahmud, A.S.; Hassan-uz-Zaman, M.; Nahian, M.A.; Ahmed, A.; Nahar, Q.; Streatfield, P.K. Health consequences of climate change in Bangladesh: An overview of the evidence, knowledge gaps and challenges. Wiley Interdiscip. Rev. Clim. Chang. 2019, 10, 1-14. [CrossRef]

18. Ferdous, J.; Mallick, D. Norms, practices, and gendered vulnerabilities in the lower Teesta basin, Bangladesh. Environ. Dev. 2019, 31, 88-96. [CrossRef]

19. Tanny, N.Z.; Rahman, M.W. Climate change vulnerabilities of women in Bangladesh. Agriculturalists 2016, 14, 113-123. [CrossRef]

20. Naz, F.; Doneys, P.; Saqib, S.E. Adaptation strategies to floods: A gender-based analysis of the farming-dependent char community in the Padma floodplain, Bangladesh. Int. J. Disaster Risk Reduct. 2018, 28, 519-530. [CrossRef]

21. Islam, S. An assessment of Women Vulnerability for Flooding Hazard and Socio Economic Condition: A Case Study on Char Gonai of Tepamadhapur Union, Kaunia, Rangpur, Bangladesh. Imp. J. Interdiscip. Res. 2017, 3, 211-231.

22. Kakota, T.; Nyariki, D.; Mkwambisi, D.; Kogi-Makau, W. Gender vulnerability to climate variability and household food insecurity. Clim. Dev. 2011, 3, 298-309. [CrossRef]

23. Speranza, C.I. Gender-Based Analysis of Vulnerability to Drought among Agro-Pastoral Households in Semi-Arid Makueni District, Kenya. In Gender and Sustainable Development: Case Studies from NCCR North-South. Perspective Volume 2; Premchander, S., Muller, C., Eds.; University of Bern: Bern, Switzerland, 2006.

24. Perez, C.; Jones, E.M.; Kristjanson, P.; Cramer, L.; Thornton, P.K.; Förch, W.; Barahona, C. How resilient are farming households and communities to a changing climate: A gender-based perspective. Glob. Environ. Chang. 2015, 34, 95-107. [CrossRef]

25. Ndlovu, T.; Mjimba, V. Drought risk-reduction and gender dynamics in communal cattle farming in southern Zimbabwe. Int. J. Disaster Risk Reduct. 2021, 58, 1-7. [CrossRef]

26. Ncube, A.; Mangwaya, P.T.; Ogundeji, A.A. Assessing vulnerability and coping capacities of rural women to drought: A case study of Zvishavne district, Zimbabwe. Int. J. Disaster Risk Reduct. 2018, 28, 69-79. [CrossRef]

27. Knight, K.W. Explaining cross-national variation in the climate change concern gender gap: A research note. Soc. Sci. J. 2019, 56, 627-639. [CrossRef]

28. Owusu, M.; Nursey-Bray, M.; Rudd, D. Gendered perception and vulnerability to climate change in urban slum communities in Accra, Ghana. Reg. Environ. Chang. 2019, 19, 13-25. [CrossRef]

29. Adger, W.N.; Barnett, J.; Brown, K.; Marshall, N.; O’Brien, K. Cultural dimensions of climate change impacts and adaptation. Nat. Clim. Chang. 2013, 3, 112-117. [CrossRef]

30. Herrick, C. Self and Place Constructs in Climate Change Vulnerability Assessments: Gaps and Recommendations. Sustainability 2021, 13, 2990. [CrossRef]

31. Sultana, F. Fluid lives: Subjectivities, gender and water in rural Bangladesh. Gend. Place Cult. 2009, 16, 427-444. [CrossRef]

32. Brown, K.; Adger, W.N.; Devine-Wright, P.; Anderies, J.M.; Barr, S.; Bousquet, F.; Butler, C.; Evans, L.; Marshall, N.; Quinn, T. Empathy, place and identity interactions for sustainability. Glob. Environ. Chang. 2019, 56, 11-17. [CrossRef]

33. Rahman, A.T.M.S.; Jahan, C.S.; Mazmuder, Q.H.; Kamruzzaman, M.; Hoson, T. Drought analysis and its implications in sustainable water management in Barind area, Bangladesh. J. Geol. Soc. India 2017, 89, 47-56. [CrossRef]

34. Bangladesh Bureau of Statistics. Population and Housing Census 2011: Zila Report: Gaibandha; Ministry of Planning: Dhaka, Bangladesh, 2015.

35. Bangladesh Bureau Statistics (BBS). Statistical Yearbook Bangladesh 2020; Government of Bangladesh: Dhaka, Bangladesh, 2021.

36. Bangladesh Bureau Statistics (BBS). District Statistics 2011 Gaibandha; Government of Bangladesh: Dhaka, Bangladesh, 2012.

37. Hoffman, A.J. Climate Change as a Cultural and Behavioral Issue: Addressing Barriers and Implementing Solutions. Organ. Dyn. 2010, 39, 295-305. [CrossRef]

38. Barnett, J.; Adger, W.N. Climate Change, Human Security and Violent Conflict. Political Geogr. 2007, 26, 639-655. [CrossRef]

39. Brown, K. Sustainable adaptation: An oxymoron? Clim. Dev. 2011, 3, 21-31. [CrossRef]

40. Stringer, L.C.; Dyer, J.C.; Reed, M.S.; Dougill, A.J.; Twyman, C.; Mkwambisi, D. Adaptations to climate change, drought and desertification: Local insights to enhance policy in southern Africa. Environ. Sci. Policy 2009, 12, 748-765. [CrossRef]

41. Turner, R.K.; Paavola, J.; Cooper, P.; Farber, S.; Jessamy, V.; Georgiou, S. Valuing nature: Lessons learned and future research directions. Ecol. Econ. 2003, 46, 493-510. [CrossRef]

42. Van Houweling, E. "A Good Wife Brings Her Husband Bath Water": Gender Roles and Water Practices in Nampula, Mozambique. Soc. Nat. Resour. 2016, 29, 1065-1078. [CrossRef]

43. Cannon, T.; Müller-Mahn, D. Vulnerability, Resilience and Development Discourses in the Context of Climate Change. Nat. Hazards 2010, 55, 1-15. [CrossRef]

44. Banwell, C.; Dixon, J.; Bambrick, H.; Edwards, F.; Kjellström, T. Socio-cultural reflections on heat in Australia with implications for health and climate change adaptation. Glob. Health Action 2012, 5, 1-9. [CrossRef] 
45. Hasan, M.R.; Nasreen, M.; Chowdhury, M.A. Gender-inclusive disaster management policy in Bangladesh: A content analysis of national and international regulatory frameworks. J. Disaster Risk Manag. 2019, 41, 101324. [CrossRef]

46. Benson, D.; Jordan, A.; Cook, H.; Smith, L. Collaborative environmental governance: Are watershed partnerships swimming or are they sinking? Land Use Policy 2013, 30, 748-757. [CrossRef]

47. Brink, E.; Wamsler, C. Collaborative Governance for Climate Change Adaptation: Mapping citizen-municipality interactions. Environ. Policy Gov. 2017, 28, 82-97. [CrossRef]

48. Dapilah, F.; Østergaard Nielsen, J.; Lebek, K.; D'haen, S.A.L. He who pays the piper calls the tune: Understanding collaborative governance and climate change adaptation in Northern Ghana. Clim. Risk Manag. 2021, 32, 100306. [CrossRef]

49. Sullivan, A.; White, D.D.; Hanemann, M. Designing collaborative governance: Insights from the drought contingency planning process for the lower Colorado River basin. Environ. Sci. Policy 2019, 91, 39-49. [CrossRef]

50. Holman, I.P.; Hess, T.M.; Rey, D.; Knox, J.W. A Multi-Level Framework for Adaptation to Drought within Temperate Agriculture. Front. Environ. Sci. 2021, 8, 1-14. [CrossRef] 